\title{
Festa pública i memorialística a la Barcelona barroca $^{1}$
}

\author{
Arantxa Llàcer Martorell \\ Universitat de València \\ arantxallacer@gmail.com \\ https://orcid.org/0000-0002-3112-2460
}

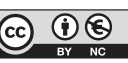

Rebut: juny de 2018 .

Acceptat: setembre de 2018 .

\section{Resum}

Una de les eines més efectives per poder conèixer amb més detall els esdeveniments de la història és la memorialística. Mitjançant l'estudi d'aquests testimonis de primera mà, ara som capaços d'esbrinar els interessos i les preocupacions del conjunt de la societat en cada període històric. Aquest article pretén descriure el funcionament general de la memorialística i les característiques dels dietaris més concretament. A través de l'estudi de dietaris institucionals catalans però també d'altres de caire privat, duts a terme per autors particulars, desgranem els detalls de la festa barroca de la ciutat comtal i entenem com els esdeveniments més rellevants afectaven la seua quotidianitat i la dels seus coetanis. Veurem amb cadascun dels testimonis elements diferents d'un mateix moment, punts d'atenció diversos davant una mateixa actualitat i, alhora, formes molt variades de fer memòria.

Paraules clau: memorialística; dietaris; història; Barcelona; institucions; ciutadans; escriptura en primera persona

\section{Resumen. Fiesta pública y memorialística en la Barcelona barroca}

Una de las herramientas más efectivas para conocer con más detalle los diferentes episodios de la historia es la memorialística. A través del estudio de estos testimonios de primera mano, ahora somos capaces de saber los intereses y preocupaciones del conjunto de la sociedad en cada periodo histórico. El presente artículo pretende describir el funcionamiento general de la memorialística y las características de los dietarios más concretamente. A través del estudio de dietarios institucionales catalanes, pero también mediante otros de carácter privado, escritos por autores particulares, desgranamos los detalles de la fiesta barroca de la ciudad condal y entendemos cómo los eventos más relevantes afectaban su día a día y el de sus coetáneos. Veremos con cada uno de ellos elementos diferentes de un mismo momento, diversos puntos de atención ante una misma actualidad y, al mismo tiempo, formas muy variadas de hacer memoria.

Palabras clave: memorialística; dietarios; historia; Barcelona; instituciones; ciudadanos; escritura en primera persona

1. Aquest estudi és part del treball dut a terme gràcies a una borsa d'estudi Ramon d'Alòs-Moner de l'Institut d'Estudis Catalans (convocatòria 2017) sobre l'erudit Jaume Ramon Vila. 
Abstract. Public celebrations and memories in the Baroque Barcelona

One of the most effective tools to learn more about the different episodes of the story is the first-person writings. Through the study of these first-hand testimonies we are now able to know the interests and concerns of society in each historical period. This article aims to describe the general functioning of the memories and the characteristics of the diaries. Through the study of Catalan institutional diaries but also private ones, written by private authors, we unclog the details of the Baroque celebrations of Barcelona. We will see with each one of the diaries different elements of the same moment, different points of attention about the same event and, at the same time, very varied forms of memory.

Keywords: memories; diaries; history; Barcelona; institutions; citizens; first person writing

\section{Sumari}

Introducció: fer memòria

Els dietaris

Dietaris institucionals

Dietaris privats
La festa narrada en primera persona

Conclusions

Bibliografia

\section{Introducció: fer memòria}

Les eines mitjançant les quals redescobrim, estudiem i entenem el nostre passat van evolucionant, la qual cosa ens permet accedir cada vegada a més i més materials que ens el narren de primera mà des de punts de vista diferents però complementaris. L'objectiu d'aquest article és recuperar un esdeveniment festiu de la Barcelona barroca a través d'autors que van dur a terme escrits en què demostraven actituds diferents davant la seua actualitat. Alhora, per poder arribar a una descripció acurada, fiable i detallada hem treballat amb una mena de testimonis que, si bé no han estat suficientment valorats pels investigadors fins fa unes poques dècades, de mica en mica van adquirint un paper rellevant en els estudis al voltant de la llengua i cultura catalanes: els escrits memorialístics.

Els textos a partir dels quals s'articula la nostra aportació són aquells que s'han emmarcat sota l'etiqueta memòria personal o memorialística, la qual acull aquells testimonis que tenen com a funció primera i essencial la de fer memòria (Escartí, 2011: 163). Tot i que els especialistes ja n'han definit i desgranat les característiques bàsiques, ${ }^{2}$ podem dir que el tret definitori de la memorialística és la intenció dels autors de deixar testimoni escrit del seu present, de l'actualitat que els envolta i de la qual en són partícips. És a dir, el mercader, el religiós o el

2. Per saber més sobre les característiques de la memorialística vegeu Amelang (2003), Escartí (1998), Jané et al. (2013), Jané i Poujade (2015), Miralles (2003) o Simon (1988). 
ciutadà (per posar tres exemples d'autors potencials) pretenen deixar constància de les seues vides i experiències —individuals i col-lectives-, perpetuar la seua existència i controlar el pas del temps. ${ }^{3}$ És el cas, per exemple, de Jeroni Pujades, que ja feia referència a aquesta condició temporal de l'individu en el prefaci del seu dietari:

i perquè la nostra naturalesa és mortal, com nos ensenya la experiència [...] i axí no podem perpetuar-nos per poder comptar i fer saber a nostres fills i pòsteros lo que passa en nostre temps, per ço és bo scríurer y dexar continuat lo que vuy passa, perquè per medi de la scriptura se puga saber en esdevenidor ${ }^{4}$ (Pujades, 1975: v. I, 67).

Perquè entenguem millor a quin tipus de textos ens referim, els investigadors han apuntat dues línies evolutives pel que fa al naixement i desenvolupament d'aquest tipus d'escrits: d'una banda, com l'evolució dels llibres de comptes i, d'una altra banda, com el desenvolupament dels cronicons o cròniques locals. ${ }^{5}$ Aquesta divisió afectarà les característiques bàsiques dels diferents tipus de testimonis memorialístics: memòries, dietaris, diaris, cròniques, llibres de família, autobiografies espirituals, etc. ${ }^{6}$

En el cas català, doncs, un dels punts d'inici dels testimonis personals es troba, d'una banda, en els llibres de comptabilitat que els mercaders feien servir per anotar els seus negocis i en què, en un moment donat, comencen a incorporar entrades de caire personal o familiar. Aquest afegit d'informació de caire privat s'entén com el punt de partida dels llibres de família (Mandingorra, 2002: 218). ${ }^{7}$

A més a més, amb l'inici d'una etapa propícia per a la memòria escrita, que eclosiona en l'època moderna, alguns feren el pas de la memòria col·lectiva a la memòria individual (Mandingorra, 2002: 223) i començaren a entendre l'escrip-

3. Aquests són alguns dels trets bàsics per definir el concepte que han aportat Jané (2013), Miralles (2003) o Mouysset (2015).

4. Totes les fonts emprades en aquest article han estat editades seguint els criteris de la col·lecció Els nostres clàssics; en els casos en què els textos ja comptaven amb una edició prèvia, l'hem revisada quan ha estat necessari.

5. Hem d'advertir, però, que les dues opcions que ací apuntem s'adscriuen a l'àmbit català, i que els testimonis memorialístics escrits en altres punts de la geografia europea seran deutors d'una altra tradició i moment històric que va definir la seua evolució. Cal fer notar que l'escriptura privada va ser un fenomen estès arreu d'Europa que en l'actualitat compta amb diversos grups d'investigació especialitzats: trobem grups de recerca especialitzats en memorialística a França (<www.ecritsduforprive.fr $>$ ), Alemanya (<www.egodocument.net $>$ ) o Itàlia (<www.bilf.uniroma2.it>). A la Península, destaquen el grup català <www.memoriapersonal.eu $>$ o, en àmbit hispànic, <www.siece.es>.

6. Entenem aquesta classificació com una eina per acostar-nos a la recerca d'aquest tipus de text, però no com una franja divisòria intransferible entre els diferents escrits privats. Els especialistes han posat en evidència que la memorialística es compon de textos molt heterogenis i difícilment aîllables sota una classificació exhaustivament delimitada.

7. Que un dels inicis dels testimonis privats siguen els llibres de comptes no és una coincidència si tenim en compte que Castillo (2015: 47) destaca el paper protagonista dels mercaders i comerciants en el període de l'edat moderna, moment d'auge de la memorialística. 
tura com una possibilitat d'anar més enllà dels límits temporals, de manera que el llibre en què escrivien simbolitzava un espai per a la representació de l'individu dins el món, la reflexió i l'autoafirmació en el conjunt de la societat, i que se centrava en una sola persona i s'adreçava — teòricament- a qui escrivia. ${ }^{8}$ Aquest canvi de mentalitat o de propòsit va marcar l'inici dels primers testimonis de dietari, diari personal o memòries.

D'una altra banda, alguns investigadors han apuntat que els dietaris escrits a manera de reculls de notícies seguien el model d'algunes de les cròniques universals que, gradualment, van evolucionar cap a cròniques de caire local (Coll i Alentorn, 1991: 428; Escartí, 2011: 170-171). La voluntat memorialística era la mateixa, deixar constància d'uns fets concrets i propers, però en aquest cas el focus d'atenció s'ampliava cap a l'actualitat del conjunt de la localitat, ciutat o comunitat on l'autor hi residia, la qual tenia conseqüències sobre els seus afers vitals.

\section{Els dietaris}

Si ens centrem en un dels tipus d'escrits memorialístics, els dietaris, encara podem fer més estret el paradigma i diferenciar-ne, en aquest cas, dos tipus: els institucionals i els privats. De totes les varietats de textos memorialístics que just abans hem esmentat, els dietaris són textos escrits amb una certa periodicitat a mans d'un autor particular que centra el seu relat en els esdeveniments i fets històrics més rellevants del seu entorn, explicats sempre des de l'experiència personal de qui escriu i el seu punt de vista particular. ${ }^{9}$

Com veurem a través de les seues característiques principals, els dietaris institucionals i privats es distingiran, a més de pel to que hi fan servir i per la selecció de continguts, per la seua intenció: si bé els textos institucionals estan escrits per ser llegits, per ressenyar els esdeveniments més importants però també per justificar les decisions de les classes dirigents i refermar una forma de pensar i d'actuar en episodis de relleu social i institucional, en els dietaris privats l'autor

8. El pas de l'escriptura col-lectiva a la individual és un procés lent que es va donar progressivament i que va assolir el seu moment de puixança en el segle XvIII (Amelang 2003: 35). Cal entendre l'afirmació d'Amelang com el punt àlgid de la memorialística, atès que ja existeixen testimonis d'aquesta mena al llarg dels segles XVI i XVII, com per exemple alguns dels testimonis que farem servir en aquest article, el Dietari de Jaume Ramon Vila i el Dietari de Frederic Despalau.

9. En canvi, els diaris recullen aspectes quotidians de qui escriu mitjançant entrades diàries; els 1libres de família contenen aquelles informacions més importants del nucli familiar (naixements, noces o defuncions) juntament amb algunes fites particulars del seu entorn més pròxim. Les cròniques o memòries històriques, que comparteixen més trets amb la dietarística, es distingeixen d'aquesta última en el seu to del tot impersonal, la seua redacció sense interrupcions i el focus d'interès sempre centrat en els episodis històrics, sense cap implicació directa de qui escriu. Els investigadors també han esmentat les autobiografies — amb l'autor esdevingut nucli de la narració- o biografies conventuals, centrades en l'experiència religiosa de qui escriu, o també dutes a terme per membres del clergat que narren la vida conventual. 
agafa la ploma per deixar testimoni escrit del seu temps i no ha de tenir necessàriament l'objectiu de ser llegit — tot i que sovint s'adreça a un hipotètic lector.

Seguint el nostre objectiu principal, recuperar el passat a través d'autors amb interessos diferents davant la seua actualitat, ens valem dels dietaris institucionals i de dietaris privats adscrits a la segona línia evolutiva que en l'apartat anterior hem anotat: dietaris hereus dels annals i els cronicons, i que segueixen les característiques bàsiques de les cròniques, és a dir, testimonis que generalment estan bastits a partir d'entrades diàries i independents - teòricament redactades just després d'assistir a l'esdeveniment que recullen-i amb la pretesa voluntat de deixar constància dels fets històrics més importants de l'entorn de l'autor, juntament amb la seua opinió personal al voltant d'allò que ens descriu (Amelang, 2003: 20).

\section{Dietaris institucionals}

Ambdós tipus de dietaris comparteixen algunes de les seues característiques, però just ací en destacarem les diferències, que conformen alguns dels seus trets definitoris. Si ens ocupem en primer lloc dels dietaris institucionals, d'entrada estem davant unes obres que no tenen un únic autor, sinó que són una mena de «llibre» que passa de mà en mà entre el funcionari o cronista encarregat de la seua redacció en cada moment. El seu objectiu principal és recollir l'activitat de la institució que el promociona, de manera que les opinions que s'hi exposen vindran predeterminades per l'òrgan al qual serveixen o el propòsit que hi ha darrere de cada testimoni; inclouen, a més a més, esdeveniments i festivitats protagonitzats per grans personalitats. Per tant, són dietaris que hem de llegir i interpretar amb un cert escepticisme perquè el resultat autojustificatiu que es vol obtenir preval al fet que s'hi narra.

Al seu torn, els dietaris institucionals no estan escrits per a un cercle reduït, familiar, sinó que recullen informacions ben diverses dels episodis més rellevants esdevinguts principalment en la ciutat comtal: la descripció d'una visita reial, un conflicte entre ciutadans o l'arribada d'uns galions, per posar ara alguns exemples. També s'hi registren els nomenaments, la correspondència, l'elecció de consellers o qualsevol fita que suposara una despesa econòmica, així com fets polítics, culturals o militars. I, a més, esdevindran dietaris consultats pels seus coetanis, extractats i referenciats en una gran quantitat d'escrits privats. En alguns casos podrem trobar-nos que els dietaris privats incorporen pamflets o correspondència per completar la narració, i aquestes eines poden provenir dels dietaris institucionals, que sovint copiaven les missives o feien referència a aquesta mena de materials efímers. Aquest transvasament d'informació d'un text a un altre ens permet afirmar que memòria privada i institucional no conformen parcel·les totalment separades, sinó que conflueixen, s'alimenten i comparteixen fonts d'informació.

L'estil narratiu dels testimonis oficials és del tot impersonal, una qüestió lògica si tenim en compte que l'escrivà o racional compleix una tasca de caire administratiu que més endavant continuarà una altra persona. Alhora, aquest tret d'impersonalitat està estretament vinculat amb la motivació que hi ha darrere 
dels dietaris institucionals: el cronista escriu per encàrrec, perquè és la seua funció, i no perquè sent la necessitat de deixar testimoni escrit d'allò que s'esdevé al seu voltant. Hem de remetre'ns, per tant, a la voluntat de qui realitza l'encàrrec, de les institucions que demostren una intenció justificativa en alguns episodis concrets. ${ }^{10}$ En els dietaris institucionals catalans que més endavant analitzarem podrem llegir al voltant de les despeses i de les decisions de les classes dirigents, de com i el perquè duen a terme una acció i no una altra. No neguem així que pretenguen fer memòria, sinó que hi ha uns altres propòsits que prevalen sobre l'aspecte memorialístic, a diferència dels dietaris privats que tenen com a element central fer memòria.

Un punt de trobada entre els testimonis privats i els institucionals és la seua forma i l'ordenació de les informacions: habitualment els dietaris institucionals segueixen un ordre cronològic i l'extensió de les entrades no és fixa, sinó que varia d'acord amb la notícia que s'hi desenvolupa; depenent del dietari de què ens valem, trobarem entrades diàries (és el cas de l'estructura del Manual de novells ardits i els Dietaris de la Generalitat de Catalunya) o entrades temàtiques (estructura que segueix el Llibre de les solemnitats de Barcelona). De la mateixa manera, els escrits privats sovint s'estructuren mitjançant entrades cronològicament ordenades, però en uns pocs casos — com ara en el cas del dietari de Jaume Ramon Vila- aquestes anotacions s'aglutinen en entrades temàtiques que desenvolupen un sol episodi esdevingut en diverses jornades. La profusió de detalls en la descripció d'una fita concreta també varia d'acord amb les intencions de qui escriu o, en el cas dels dietaris públics, de qui aporta el capital econòmic.

\section{Dietaris privats}

Si fins ací hem tractat de desgranar alguns trets dels dietaris institucionals, cal que ens ocupem ara de les memòries privades i de les seues característiques definitòries. Pel que fa als dietaris particulars o privats cal esmentar, en primer lloc, que allò més habitual és que sovint abasten un període de la vida de qui escriu. Seguint Escartí (1998: 10-12), els dietaris són obres d'un sol autor, per tant, no és un text que passe de mà en mà (com per exemple sí que passa amb els llibres de família, que s'hereten entre els homes del nucli familiar). El límit temporal el sol marcar la seua vida, perquè narra les vivències de qui l'escriu, el que ell mateix ha viscut, allò que algú li ha contat o allò que és de coneixement popular. ${ }^{11}$

Destaca com un tret distintiu i particular d'aquests testimonis la vinculació intransferible dietari-autor, que en el millor dels casos ens permet anar més enllà de l'esdeveniment que s'hi narra quan l'autor hi reflecteix el seu parer i el dels

10. No podem deixar de banda la importància que rebrà el càrrec de cronista oficial del Principat al llarg de l'edat moderna, especialment en anys convulsos, i que serà el motor que incentivarà una gran quantitat de textos justificatius i de caire patriòtic.

11. Però, amb l'aparició de la protopremsa o, més endavant, de la premsa periòdica, molts autors copiaran notícies publicades a diaris o directament inclouran al dietari el retall d'allò que els interessa, més enllà de les seues vivències particulars. 
seus coetanis davant una fita concreta. L'expressió més o menys explícita de les opinions de qui escriu està estretament relacionada, al seu torn, amb el grau d'intimitat i privacitat de les obres que produïen. Miralles (2003: 208) ja apuntava que «teòricament, un dietari és un llibre de lectura restringida [...] i, per tant, un text on qui escriu en té prou a deixar constància del seu punt de vista, sense necessitat de justificar-se ni de pensar en un públic divers, d'entrada» però la pràctica dista molt d'aquest principi, especialment entre els autors que escriuen dietaris pensant en un lector que no ha de pertànyer necessàriament al seu cercle més íntim.

A diferència dels testimonis institucionals, en els dietaris privats es fa més difícil definir quina és la intencionalitat del text, més enllà del seu caràcter perdurable. Però, de vegades, podem establir algunes hipòtesis basant-nos en el seu entorn sociocultural i intentant desxifrar-ne les motivacions personals que, sovint, se'ns presenten com un secret difícil de descobrir. ${ }^{12}$ En aquest sentit, cal destacar que el fet que no necessitem dur a terme cap procés per tal de desxifrar les claus de lectura dels dietaris i la resta de documents que l'integren ens indica que preferien ser accessibles. En opinió d'Amelang (2003: 228), tot i que els autors donaren a conèixer les seues intencions o declararen la privacitat de l'obra, en realitat esperaven, fins i tot desitjaven, que els seus testimonis foren llegits.

Un dels punts d'unió entre testimonis institucionals i privats és l'heterogeneïtat pel que fa a la forma de les notícies. En un mateix dietari privat podem trobar relats minuciosos en què se'ns descriuen tots els detalls d'un fet i, a continuació, l'autor pot passar a documentar un altre esdeveniment amb escassa informació o, en ocasions excepcionals, referint-nos a una altra font d'informació. Respecte dels continguts, la temàtica en general és molt variada, és difícil acotar els temes pel fet que aquests depenien de l'elecció dels autors, i, per tant, la selecció d'unes notícies o d'unes altres ens ha d'orientar sobre les inquietuds de l'escriptor. A grans trets, i en contraposició als dietaris institucionals, sí que podem establir dues grans temàtiques: assumptes de caire públic i assumptes de caire privat.

Malgrat que la denominació de «personal»o «privat» pot confondre el lector pel que fa al procés d'elaboració i la reflexió que hi ha darrere d'aquest tipus d'escrits, el fet que siguen escrits personals i conformen un tipus d'escriptura molt heterogeni no ens ha de fer pensar que parlem de textos desordenats, víctimes del que Amelang (2003: 75) denomina «desaliñada naturalidad», sinó que segueixen una estratègia que varia segons l'autor i el text que confegeix ${ }^{13}$ —altrament, alguns dietaris que es van crear a partir de notes prèvies no haurien resultat obres tan acurades com, de fet, ho són.

12. En aquesta línia, Escartí (1990: 123) ja feia notar la manca de pròlegs o textos justificatius que encapçalaren els dietaris privats, just per aquesta adscripció a l'àmbit privat que no fa necessària cap exposició de motius o justificacions.

13. Aquesta estratègia discursiva pot estar basada en aspectes diferents com l'ordenació cronològica, la forma de les entrades, la temàtica que hi recull, l'aprofitament de materials complementaris o els diferents objectius del seu testimoni memorialístic, per esmentar algunes opcions. En alguns casos també cal tenir en compte si el text ens ha arribat en una versió definitiva o si, en canvi, treballem a partir d'un esborrany o un trasllat incomplet. 


\section{La festa narrada en primera persona}

Com ja havíem avançat, el nostre objectiu final és descriure un esdeveniment festiu de la Barcelona barroca a través de memòries de caire diferent, concretament mitjançant els dos tipus de dietaris que en el punt anterior hem definit. Hem escollit un episodi amb el suficient ressò com per afectar els diferents perfils socials de la Barcelona del XVII, les exèquies a la mort del bisbe Joan Dimes Lloris el 1598. Una fita d'aquesta magnitud suposava una processó, literalment, de personalitats locals i foranes, i una presència institucional remarcable, i que també calava en els estrats més baixos de la ciutat, atés que el cos del difunt recorria els carrers de Barcelona davant la mirada de tota la població.

Per veure'n el desenvolupament extractem, en primer lloc, els dietaris catalans institucionals; ens servim dels Dietaris de la Generalitat de Catalunya (DGC) i també del Dietari de l'antic consell barceloní o Manual de novells ardits (MNA). Els DGC contenen les anotacions manuscrites a càrrec dels cronistes de la Generalitat i hi trobem notes al voltant d'una multiplicitat de temes (política, economia, societat, cultura, etc.) esdevinguts a Barcelona i a Catalunya. Pel que fa al segon testimoni era, per definició, el dietari del racional de la ciutat de Barcelona en què es registraven els nomenaments, la correspondència més rellevant, l'activitat vinculada amb els consellers o qualsevol tramesa que suposara una despesa.

Si ens centrem en les dades aportades pels DGC al voltant de la mort del bisbe el 1598, veurem que l'única informació que obtenim és mitjançant unes notes breus integrades en les notícies d'aquell any, molt sumàries. Les poques referències a l'esdeveniment que ens ocupa estan redactades a manera de resum, amb frases curtes, com veiem a continuació:

Dimecres, a XII. En aquest die se feu la sepultura del dit senyor bisbe en la Seu, y feren-li capella ardent; feren-li la volta de la professó de Corpus al revés; anarenhy totes les ordes y parròchias, e los concellers derrera ab lo lloctinent general y marquès de Aytona y molts altres. Feu-se-li molt cèlebre sepultura; sermonà-y lo pare Prado. No y anaren los senyors diputats perquè no·s trobà que y anassen altres vegades (DGC: v. III, 317).

L'aportació dels DGC destaca la presència —i absència- d'algunes personalitats destacades, però la descripció de l'esdeveniment en qüestió és pràcticament inexistent. El segon dietari institucional que hem consultat, el Manual de novells ardits, fa servir un mecanisme diferent, en lloc de contenir una narració pròpia, remet el lector a una altra font d'informació. Malgrat que l'esdeveniment també s'hi descriu sumàriament, a diferència del DGC en aquest cas el racional es refereix al moment en què el bisbe emmalaltí, el 5 d'agost del 1598 i, una mica més endavant, fins i tot extracta un parlament després que el bisbe reba l'extremunció; diu, «que estava aparellat per a tot allò que lo Senyor de tot lo món disposaria de sa persona, y que si moria ell se recordaria de pregar a Déu per aquesta ciutat» (MNA: v. VII, 121). Uns pocs dies després, el 12 d'agost, coincidint amb la festa de Santa Clara, s'esmenten les exèquies i el soterrament, i el racional ens remet a 
una altra font d'informació que analitzarem una mica més endavant, el llibre de cerimònies de la ciutat:

Dimecres XIJ, festa de santa Clara. Dit dia fonc soterrat lo cors del dit senyor bisbe de Barcelona, dins la capella de sanct Pacià de la Seu de Barcelona, ab tota la solemnitat necessària, fent-li per la ciutat la volta acostumada. La serimònia de la qual sepultura y tot lo que passà an aquella, y los dies que han discorregut del dia de la sua mort fins al dia present, està llargament scrit y continuat en lo libre quint de les serimònies de la present ciutat (MNA: v. VII, 121).

Com podem comprovar, l'única informació afegida pel MNA respecte dels DGC és el lloc concret del soterrament de Dimes Lloris, a la capella de Sant Pacià, i redueix la resta de la cerimònia a un esdeveniment amb «la solemnitat necessària». Si sols ens servírem dels testimonis institucionals aquesta és tota la informació que conservem de les exèquies a la mort de Joan Dimes Lloris, qui va ser bisbe a la ciutat comtal durant més de dues dècades.

Davant aquest buit informatiu, ens remetrem a continuació a dues memòries privades que ens valdran per completar la narració. Un dels trets més definitoris de les memòries privades és que sovint són un reflex de les motivacions, preocupacions i interessos dels seus autors. Perquè puguem veure aquesta característica, estudiarem a continuació dos dietaris, el de Frederic Despalau i el de Jaume Ramon Vila, que recullen el mateix esdeveniment però amb diferències força interessants.

En primer lloc, Frederic Despalau era un noble barceloní, diputat militar el 1585 i drassaner major de la Generalitat, membre habitual de les ambaixades i delegacions que la Diputació enviava al Consell; va estar al càrrec de les construccions navals i de les obres a la Drassana. Era, per tant, un personatge influent i que es movia en un cercle bastant selecte (Simon, 1991: 93-94). Mentre duia a terme aquestes activitats vinculades a les institucions del Principat, va recollir alguns dels esdeveniments polítics de la història catalana, principalment de la ciutat de Barcelona, en un dietari.

Es tracta d'un text amb una estructura cronística, que ens ha pervingut escrit com una mena d'esborrany. Pel que fa a les seues característiques, i seguint la descripció que en fa Simon (1991: 91-92), ${ }^{14}$ el dietari està escrit principalment en tercera persona, fins i tot en els episodis en què Despalau intervé com a personatge, i no fa referència a assumptes personals o familiars. Al llarg del testimoni, que ressenya alguns dels esdeveniments més importants de la història catalana d'entre 1572 i 1600, trobarem d'una banda el testimoni original de Frederic Despalau — que inclou parlaments de personatges rellevants com el rei, una tàctica habitual en aquesta mena d'escrits - i, d'una altra banda, fragments provinents de l'obra de Jerónimo Zurita Anales de la Corona de Aragón. Hi destaca, per la

14. Simon, en aquest mateix llibre, aporta l'edició del dietari de Despalau, juntament amb la de les memòries de Perot de Vilanova i Jeroni Saconomina. 
seua singularitat, el fet que la primera meitat del dietari no segueix un ordre cronològic estricte, sinó que hi ha salts temporals en les entrades.

Pel que fa a la informació que ens aporta al voltant de les exèquies del bisbe Dimes Lloris, Despalau esmenta que el 5 d'agost el bisbe estava malalt i que el dugueren a combregar a la Seu; descriu les personalitats que hi acudiren i per què foren convidades - i puntualitza: «no u trobaren se convidessin virey ni consellés en semblants coses»-i, a continuació, es refereix a la processó per dur el tàlem al bisbe:

Convidaren, per les dues vares [que] sobraven, a don Federich Despalau y a Yaume de Aguilar, senyor de Castellet. Y portaren lo tàlem ab los quatre consellés, ysqueren per lo portal mayor de la Seu, abaxaren les escalles, vingueren per la plasa Nova, muntaren al Palau; en la profesó anave lo capítol y tot l'altio $r$ r clero. Lo duc de Feria abaxà al peu de la escala, aconpanyà lo Sant Sagrament, entrà en la cambra del bisbe y los consellés; donà-li a conbregar lo canonye Mas, en latí se digueren totes les paraules. A la tornada volgué lo virey portar la vara del tàlem, los consellés digueren a Aguilar dexàs la sua, y portaren lo tàlem lo virey y los quatre consellés y don Federich Despalau, [que] anaren per la Libretaria y Carsetaria y plasa del Rey y per devant lo Palau Real, y tornaren a la Seu ab molta luminària y molts cavallés y molt poble, que paragué molt bé a tots (Simon, 1991: 152).

En aquest fragment podem comprovar com Frederic Despalau és un dels personatges que intervenen en l'esdeveniment però el descriu en tercera persona, des de la distància. Destaca la multiplicitat de detalls com ara les persones que hi assisteixen, i els moments clau com la presència del duc de Feria acompanyant el Sant Sagrament o el desenvolupament de tot l'acte en llatí. Però, d'acord amb els interessos de l'autor, els noms dels qui hi assistiren semblen quedar per sobre de la cerimònia en qüestió, que queda resumida en unes poques oracions. Després d'aquesta informació, la narració salta directament al dia 8, quan va morir el bisbe, i trobem una descripció molt més breu, sumària, semblant a la que havíem llegit en els dietaris institucionals:

A 8 morí dit bisbe. Tres dies anaren les parròquies y altres monestís ab sobrell, y tota la ciutat, y besaven-li les mans y la roba. Al soterrar convidaren los consellés, com a cap del dol que eren, lo duc y marquès d'Eytona [sic], y tots los eclesiàstics, nobles y militars y ciutadans [que] eren en la ciutat. Feren la volta del Corpus al revés; anaren les parròquies y monestís y més de 150 atxes; y feren capella ardent (Simon, 1991: 153).

Aquest fragment ve seguit d'una breu enumeració de les personalitats que assistiren a les exèquies, especialment aquelles més rellevants com el virrei, marquesos i abats, i tanca la narració de l'episodi i l'enumeració resumint els assistents com «molts cavallés y ciutadans com tenen de costum agraduar-se». Ens sobta en aquest cas que, a diferència del fragment anterior, la narració al voltant de les exèquies és molt més breu i el fet que, tractant-se d'un esdeveniment marcadament religiós, els elements destacats per Despalau són, novament, els assis- 
tents. Aquesta selecció d'informació, però, no és més que un reflex de qui escriu $i$, en conseqüència, dels seus interessos personals.

En segon lloc, ens referim al dietari de l'historiador i religiós barceloní Jaume Ramon Vila. ${ }^{15}$ Vila provenia d'una família benestant $i$, gràcies a una vida econòmicament acomodada, va dedicar la seua vida a l'escriptura i la devoció, de manera que va deixar una gran llista d'obres de caire històric de les quals tenia còpia, va produir textos de caire religiós, heràldic i amb matisos històrics importants. Atret per les seues aficions lectores i escriptores, va dur a terme un dietari que fins ara no ha estat gaire estudiat. Aquesta obra memorialística ens ha arribat mitjançant un trasllat parcial $\mathrm{i}$, fins on apunten les nostres investigacions, podria haver-se tractat d'un dietari més extens, dividit en diversos volums, del qual sols ens han arribat les notícies corresponents als anys 1596-1601 de manera incompleta.

Cal que destaquem, tot i que no ens podem detenir a descriure el testimoni, que el dietari, així com ens ha pervingut, és una mostra bastant clara i inequívoca dels interessos del seu autor, dels seus pensaments i de les seves inquietuds, $\mathrm{i}$ alhora pensem que va estar escrit per ser llegit pel seu entorn intel-lectual més proper. És per això que el contingut religiós d'aquest testimoni parcial ocupa prop del $40 \%$ del dietari, tot i que a hores d'ara ja podem parlar d'alguns episodis religiosos que haurien format part de l'obra autògrafa i que no estan traslladats al manuscrit amb què treballem. ${ }^{16}$

Si ens centrem en l'episodi que ens ocupa, d'entre tots els testimonis que fins ara hem presentat, aquest és el que ens aporta més informació. Hi destacarem, per tant, els aspectes més cridaners i alhora més diferents respecte de la resta de dietaris que hem vist. D'entrada, l'autor no es limita únicament a les exèquies sinó que descriu els dies previs a la mort del bisbe i es remet a quan apareixen els símptomes més evidents de la seua malaltia, el 25 de juliol de 1598:

de la qual consecració restà tan cansat lo bisbe de Barcelona, axí per sa edad com per fer lo temps molt calorós, que al cap de pochs dias se enmalaltí de una febra molt aguda y, aumentan-li lo mal, fou ordenat per los metges que li aportassen lo viàtich (AHCB, ms. B-100, p. 162).

El de Vila és l'únic testimoni fins ara que ha posat data concreta a l'inici del declivi del bisbe, i aquesta tendència a aportar-nos una cronologia detallada serà una constant al llarg de l'episodi. La propera informació que recull ja és dels primers dies d'agost, concretament del dia 5, d'acord amb les informacions que ja hem extractat del MNA i el dietari de Despalau, i es referirà a com l'estat de salut del bisbe va empitjorant fins demanar l'extremunció el 7 d'agost. De l'episodi del 5 d'agost esmenta que:

15. El dietari, que roman inèdit, es conserva a l'Arxiu Històric de la Ciutat de Barcelona (en endavant $\mathrm{AHCB}$ ) i correspon a la signatura B-100. Per veure més dades al voltant de l'autor i la seua obra, vegeu Llàcer (2016; 2018).

16. Tractem aquest aspecte de l'obra en Llàcer (2016). 
tragueren en dita Seu, ans de dir matynes, lo santíssim Sagrament ab la custòdia canonical cuberta ab camiseta de tafetà blanch, sobre lo altar mayor [...]; li aportaren lo sant Sagrament processionalment com és acostumat: acompañat de tots los capellans, pabordes, domers, canonges y dignitats de dita Seu, aportant lo tàlem los quatre concellers y don Federich Despalau y mossèn Jaume de Aguilar; lo sant Sagrament aportave lo canonge Garau Mas, un dels quatre domers canonges, servint-li de assistens los dos sacristans menors vestits ab sobrepellissos y estolas, y detràs venia molta gent y poble.

[...] entraren dins lo Palau Episcopal, hont estava malalt dit senyor bisbe, lo qual estava en lo llit, y sobre lo llit tenia la capa de cos estesa, y ab roquet y estola vestit; y en la cambra éran arribats abans lo virrey y lo sobredit bisbe de Gerona, los quals, juntament ab los concellers, éran estats convidats per dita ocasió per lo senyor bisbe de Barcelona (AHCB, ms. B-100, p. 161-162).

A diferència de les dades aportades pels testimonis anteriors, el focus d'atenció de mossèn Vila no seran les personalitats de caire institucional, sinó que el seu interès recau en la descripció dels elements religiosos (la custòdia o les vestidures del bisbe en el llit) i la presència de canonges, capellans, pabordes i, en general, persones vinculades a l'Església, de manera que la figura del virrei o dels consellers s'esmenta de passada. Fins i tot, malgrat que el mossèn coneix la rutina de funcionament d'aquests esdeveniments, i potser els seus lectors potencials també, es referirà als carrers que conformen la volta del Palau Episcopal a la Seu, tot i que ací no ens detindrem a enumerar-los.

Una vegada arribem a la data clau, el 8 d'agost, quan mor el bisbe, Jaume Ramon Vila començarà un relat molt acurat de tot el que passarà a la ciutat comtal en els dies següents; a diferència dels testimonis que hem vist fins ara, de la sintètica fredor dels DGC i del MNA a la «pretesa distància» de Despalau, Vila s'implica en el relat i detalla els fastos de l'Església a propòsit de l'esdeveniment.

Algunes de les dades que podem extraure d'aquest episodi són, per exemple, com es disposa la sala gran del Palau Episcopal on romandrà el cos del bisbe fins al soterrament:

posaren a punt la sala gran del Palau Episcopal per la solemnitat de las funeràrias, empaliant-la tota de dol y fent en ella set altars: hun de gran en lo cap de la sala y tres a cada costat, y en lo mitg feren un gran túmol sobre moltas grades. Y mentre assò se feya, enbalsamaren lo cos i.l vestiren de pontifical, posant-lo de aquesta manera ab unas andas o flors de morts, cubertas ab un imperial de la Seu, en la capella del palau que està al cap de la sala primera (AHCB, ms. B-100, p. 162).

Se'ns explica, a continuació, que la sala gran del palau no estava preparada l'endemà al matí, de manera que el cos va romandre a la capella fins que el van poder traslladar; va ser a la sala gran del Palau Episcopal els dies següents, disposada segons ens indica Vila: «estigué lo cos a la sala ab la forma sobredita, y ab lluminària continua de 12 atxes, $\mathrm{y}$ en tots los altars se digueren moltas missas baxas [...], al qual [i.e. palau] assistían los concellers vestits ab gramallas de dol y los parents del bisbe ab los mermesors» (AHCB, ms. B-100, p. 164). 
D'aquest capítol del dietari destaquem la qualitat de les descripcions que s'hi aporten, l'autor no sols s'interessa pel desenvolupament de l'esdeveniment concret, sinó que sovint també ens proporciona dades sobre com estava disposada la sala, la capella i la Seu, i també descriu les personalitats, com van vestits, etc. Així com sabem amb certesa que Frederic Despalau havia participat dels actes fúnebres, en el cas de Vila no se'ns fa tan explícita la seua presència, però si ens basem en el seu estatus social i en la seua capacitat de descripció, no ens sobtaria que haguera estat present en les cerimònies que en aquest episodi ens narra.

Per tant, i tornant al desenvolupament de l'acció, arribem al dia quan se celebren les exèquies, el 12 d'agost de 1598. L'autor es refereix a les personalitats que hi participen (els consellers, el virrei, el marquès d'Aitona, l'abat de Banyoles i un llarg etcètera) i al fet que, una vegada han arribat al Palau Episcopal, es duu a terme una processó fent el recorregut del Corpus a la inversa, com era costum:

primerament anaven més de sinquanta còvens ab pa de dintre cubert ab tovallas blancas que.1s aportaven donas al cap, y tras d'ells venían sinquanta atxas de la ciutat ab escuts de las armas de la ciutat, aportant-las pobras vestits ab gramallas de dol; aprés venían la creu mayor de la Seu y, tras d'ella, totas las de las parròquias y monastirs de la present ciutat. Aprés venia lo clero de Santa Maria de la Mar y aprés tot lo altro clero de las altres parròquias; aprés venían tots los ordes agraduats com lo dia de Corpus y aprés d'ells venia lo clero y Capítol de la Seu, aportant lo cap de professó lo molt il·lustre y reverendíssim senyor don Francesch Arévolo[sic] y Suaso, bisbe de Girona, que feu lo offici de pontifical (AHCB, ms. B-100, p. 164-165).

Si fins ara havíem pogut accedir a conèixer amb detall què es fa amb motiu de les exèquies, qui hi assisteix i com van vestits, en aquest punt de la narració Jaume Ramon Vila es refereix, quasi necessàriament, al clima i les seues conseqüències. Amb l'ordre de la processó descrit, remarca el fet que feia molta calor i que el túmul anava molt alt, cobert de brocat vermell i dut per bastaixos, però com, a conseqüència de les temperatures, el cos, que anava descobert, es veia «molt negra y escares, y sentia molt perquè no lo havían ben embalsemat» (AHCB, ms. B-100, p. 165); sens dubte, aquesta no és una informació que fàcilment puguem trobar en testimonis oficials. L'autor, com a espectador de primer ordre, encara ens detalla que les personalitats que anaven al voltant del cos, anaven cada vegada més desordenades perquè «per sentir lo cos tant no podían anar arenglats, ni ab la ordenança deguda perquè tots se apartaven del túmol tant quant podían» (AHCB, ms. B-100, p. 165). Seguien l'ordre de la processó la família dels capellans i patges del bisbe, atxes, virrei, consellers i altres personalitats $i$, just al final, la família directa de Dimes Lloris.

Una vegada feta la volta del Corpus a la inversa, com ja hem dit, arriben a la Seu, posen el cos del difunt en la capella ardent i envoltat de tota la lluminària que l'acompanyava en la processó. L'ornamentació de la Seu sembla sobtar d'alguna manera Vila, que explica com estaven situats els elements d'una forma tan detallada que ens permet imaginar l'escenari de l'acció sense problemes: 
las dos-sentas atches posaren per las brandoneras que estaven en lo entorn de dita capella y arribàvan fins a las rexas de l'altar mayor, posadas a manera de gradas de teatro ab gentil orde. Y, a més de la sobredita lluminària, estaven dins la capella [...] quatre ciris de pes de més de vuit lliures cada hun, y en la còpula de dita capella estaven sinch atchas, ço hés, una al cap y altre a cada cantó, sobre los quatre pilars que sustentàvan dita cúpula, y per tota ella estaven compartits, que parexían tiara, tres-cents y vint-y-sinch siris de pes de mitja lliura cada un (AHCB, ms. B-100, p. 166).

Una vegada ha descrit l'espai on s'esdevé l'acció, l'autor parla de la missa d'una manera més sumària, destacant la nòmina de personalitats que durant l'ofici oferiren ciris per l'ànima del difunt. L'única dada sobre la quantitat de públic que hi assistí ens la proporciona un fragment en què se'ns informa que el sermó es va haver de fer en una trona portàtil perquè hi havia un «gran concurs de gent». Una vegada acabat l'ofici, els fossers soterren Dimes Lloris a la capella de Sant Pacià, com el bisbe havia demanat, sense la presència de ningú a causa de l'olor que feia el cos. Conclou el capítol amb uns paràgrafs en què es refereix als càrrecs que havia ostentat el bisbe, totes les accions pietoses que va fer per la ciutat $\mathrm{i}$ les seues virtuts.

Tanca l'episodi la reflexió del dietarista esmentant que «voler dir las suas virtuts com seria rahó seria may acabar» (AHCB, ms. B-100, p. 169), unes paraules que demostren l'admiració que sentia Vila per Dimes Lloris i que, alhora, ens fa pensar en una relació més estreta entre l'autor i el difunt; en cas que aquest vincle que estem apuntant fora real, les motivacions que hi ha darrere de la redacció d'aquest capítol se'ns presentarien del tot evidents, tot i que pel perfil biogràfic de l'autor ja som capaços de justificar la incorporació de les exèquies al dietari.

Analitzat el relat dels testimonis oficials i els dietaris privats, cal que recuperem una referència esmentada just a l'inici d'aquest epígraf. En parlar dels dietaris institucionals ens hem referit a un llibre de cerimònies, que, si bé no pot considerar-se un dietari, funciona com una mena de memòria dels grans esdeveniments que afectaren la ciutat comtal, el Llibre de les solemnitats de Barcelona. D'acord amb el propòsit inicial d'aquest testimoni, hi trobem una descripció més acurada de la notícia que ens ocupa si el contrastem amb la resta de dietaris oficials que hem extractat adés, tot i que el relat destaca el paper dels consellers, virrei i oficials de la ciutat, de manera que inverteix molts esforços a descriure les accions d'aquests per sobre de l'esdeveniment en qüestió.

De fet, les primeres anotacions d'aquesta «solemnitat» es dediquen a explicar que els consellers es reuniren en casa del notari de la ciutat - i alhora autor del capítol que narra aquestes exèquies - Francesc Pedralbes, per veure com s'havia procedit abans en una situació semblant i imitar-la. Una vegada queda justificada la seua manera d'actuar, el capítol serà, en general, una llarga llista de personalitats assistint a les misses i sepultures, informacions que destaquen per sobre del nucli de l'acció principal: les exèquies a qui havia estat bisbe de la ciutat durant més de dues dècades. Sí que cal remarcar que, a diferència dels altres testimonis a què ens hem referit fins ara, aquest és el relat que ens aporta més informació al 
voltant dels dies posteriors a la mort del bisbe i abans del soterrament; però, com ja hem dit, està centrat en les accions dels consellers, com estan distribuïdes les personalitats assistents a les exèquies, etc., i, per tant, en algunes ocasions s'assembla més a un decàleg d'accions a dur a terme per part dels consellers, virrei i personalitats diverses que intervenen en un acte d'aquest tipus. Vegem-ne un exemple:

Y fa advertir ab altra occasió que en semblants sepultures no vagen los senyors concellers tant atràs com anaven, sinó que vagen tant serca com puguen del cors, ço és aprés dels capellans, que aniran ab sobrepellisos y atxes, després del cors, per lo que aquesta vegada [...] restaren tant atràs que apenas veren lo llit o túmol del dit cos, y axí se fa assí la present nota per memèria del sdevenidor (Duran i Sanabre, 1947: v. II, 96).

Un altre element destacable és l'alt grau de coincidència que trobem entre la narració d'aquest llibre de solemnitats i el testimoni de Vila quan es descriu la processó del 12 d'agost, així com la referència a l'olor del cos del bisbe, ja que en el Llibre de les solemnitats de Barcelona també s'esmenta que les persones que havien d'anar acompanyant el difunt «no volgueren anar en dit loch per lo que dit cors pudia molt, per causa de les grans calors, y per no ésser estat ben embalsemat» (Duran i Sanabre, 1947: 95).

Aquest punt d'unió, no sabem ben bé si fortuït, ens dona peu a fer algunes observacions. D'entrada, podem afirmar que els testimonis personals poden basar-se en els testimonis oficials o institucionals com, de fet, ho fan. Malgrat que no trobem nexes suficientment forts per afirmar que Vila havia consultat el Llibre de les solemnitats de Barcelona, fins i tot podem veure les coincidències dels dos relats com el producte de dues persones que han assistit a les funeràries $\mathrm{i}$ que conten la informació de primera mà, de manera que, a grans trets, no pot distar gaire un relat de l'altre. Ara bé, com que Vila se serveix dels dietaris institucionals en altres moments del dietari, perquè en fa referència explícita, ${ }^{17}$ no seria estrany que ho haguera tornat a fer ací i haguera omès la font d'informació. Tot plegat ens permet afirmar que els dietaris institucionals i els privats no són testimonis aillats, sense punt de trobada, sinó un reflex divers d'uns mateixos esdeveniments.

17. Per posar-ne algun exemple concret fent servir els testimonis que extractem en aquest article, Jaume Ramon Vila en el dietari es refereix a la Casa de la Ciutat quan copia una carta, diu: «copý esta de l'original que-m dexaren de Casa la Ciutat» (AHCB, ms. B-100, p. 221). També coincideixen altres cartes copiades, principalment, com ara la del rei Felip III anunciant les seues noces a Barcelona (localitzat a les pàgines 206 i 207 del dietari i a la pàgina 153 del volum VII del MNA). A més, Vila s'identifica com un usuari d'aquesta font quan, en múltiples ocasions, ens remet a on trobar algunes informacions que no copia, com ara quan diu que «en lo 22 llibra del Dietari de Casa de la Ciutat de Barzelona en las primeres cartes començant en lo any 1597 [...] se trobaran algunes altres cosas acerca de dits negocis» (AHCB, ms. B-100, p. 97). Per saber-ne més sobre l'ús de fonts en els dietaris, vegeu Llàcer (2015). 


\section{Conclusions}

De l'anàlisi dels diferents testimonis podem extraure, en primer lloc, que la memòria que considerem de caire públic i aquella que hem denominat privada són dues eines complementàries quan tractem de conèixer el passat des de diferents perspectives. En aquest cas hem estat capaços d'accedir al desenvolupament de les exèquies a la mort del bisbe Joan Dimes Lloris des dels punts de vista d'un cronista, un racional, un diputat militar i un historiador i religiós, i totes les narracions posen el focus d'atenció sobre figures i accions diferents, de manera que la millor forma de crear un relat complet és unint les versions de què disposem.

En segon lloc, per dur a terme aquesta tasca de recuperació d'un episodi ens hem servit de tres tipus de testimonis: memòria de caire institucional, memòria privada i un tercer tipus d'escrit que, si bé no s'adscriu a la dietarística com a tal, també presenta les característiques d'una memòria de caire institucional. Aquesta diversitat ens ha permès comprovar com, depenent de l'autor - $\mathrm{O}$ autors-, la narració posa l'atenció en elements diferents. D'una banda, els dietaris institucionals tenen com a element nuclear allò que és més proper a l'òrgan al qual serveixen (consellers, virrei, Diputació, etc.) i el seu paper dins la fita concreta.

És a dir, els DGC i el MNA destaquen, tot i que de manera molt general, la sumptuositat de l'esdeveniment i la presència d'algunes de les personalitats més importants; al seu torn, els dietaris privats aporten dades més concretes, però alhora diferents: Despalau, pel seu perfil de prohom associat a les institucions, destaca la presència dels consellers, del duc de Feria o el marquès d'Aitona, mentre que Vila aporta més dades al voltant de l'ofici religiós i les personalitats vinculades a aquest entorn: el bisbe de Girona, el capítol de la Seu o les parròquies i els monestirs de la ciutat comtal. A meitat de camí entre la sobrietat institucional i la profusió de detalls del testimoni de Vila, trobem el Llibre de les solemnitats de Barcelona que, atès el seu propòsit de recollir esdeveniments relacionats amb grans personalitats, no pot estar-se de descriure les exèquies amb certa profunditat, alhora que destaca constantment el paper dels consellers i del virrei i es refereix a l'absència dels diputats per qüestions protocol-làries.

L'anàlisi dels dietaris privats ens dona resultats diversos, i això és conseqüència d'un tret inherent a aquest tipus d'escrits: l'element privat que permet a cada autor decidir quina informació considera rellevant i fins a quin punt vol descriure un esdeveniment o un altre. Trobem per tant un dietari privat que aparentment passa per sobre de les exèquies del bisbe quasi de puntetes enfront d'un altre testimoni que aporta una multiplicitat de detalls: Frederic Despalau ofereix una narració més semblant als dietaris institucionals, neutra, amb poc de detall i que resumeix l'esdeveniment en poc més de dos paràgrafs; en contraposició, Jaume Ramon Vila dedica fins a dos capítols a tractar el mateix tema. Vila, com a membre de l'estament religiós, destaca el procés de les cerimònies, les persones de l'àmbit religiós que hi assisteixen i aporta uns matisos i uns detalls que no trobem en Despalau. L'extensió dels dos capítols ja ens indica que la importància que donen a l'episodi és ben diferent, també perquè els seus interessos particulars i privats ho són. 
Malgrat les diferències, no queda cap mena de dubte que la memorialística és una eina cada vegada més important per reconstruir el passat. Al mateix temps, aquesta mena de testimonis tenen unes particularitats que sovint sobrepassen els límits de la disciplina històrica i ens acosten a l'actualitat de l'autor des d'una perspectiva única. L'escriptura personal és el reflex dels pensaments i les vivències dels seus autors en primera persona, que en la majoria dels casos no estan supeditats a un òrgan o institució; és, per tant, una eina que hem de començar a incorporar a les nostres recerques per tal de tenir una perspectiva completa de la nostra història, bé siga per conèixer el desenvolupament d'una gran guerra, d'un esdeveniment de la importància d'unes Corts o, en altres ocasions, per poder imaginar i reconstruir una cerimònia solemne, una pintura, una escultura, la roba, els sons i els pensaments del dia a dia d'una ciutat.

\section{Bibliografia}

Amelang, J. (2003). El vuelo de Ícaro. La autobiografía popular en la Europa moderna. Madrid: Siglo XXI.

Castillo, A. (2015). «El alfabeto y el calendario. Libros de cuentas y libros de memorias en el Siglo de Oro». A: Jané, O., Poujade, P. (eds.). Memòria personal. Construcció i projecció en primera persona a l'Època Moderna. Madrid: Casa de Velázquez, 45-62.

Coll i Alentorn, M. (1991). Historiografia. Barcelona: Curial Edicions Catalanes / Publicacions de l'Abadia de Montserrat.

DGC = Dietaris de la Generalitat de Catalunya, dir. de Josep Maria Sans i Travé. Barcelona: Generalitat de Catalunya, 1999, v. III.

Duran, A., Sanabre, J. (1947). Llibre de les solemnitats de Barcelona. Edició completa del manuscrit de l'Arxiu Històric de la Ciutat, v. II (= 1564-1719). Barcelona: Institució Patxot.

Escartí, V. J. (1990). «Unes consideracions sobre la dietarística valenciana del segle XVII». Caplletra, 9, 119-129.

-(1998). Memòria privada. Literatura memorialística valenciana del segle XV al XVIII. València: Edicions 3 i 4.

—(1999). «Introducció». A: J. Aierdi. Dietari. Notícies de valència i son regne de 1661 a 1664 i de 1667 a 1679. Barcelona: Barcino.

—(2011). «Sobre els primers testimonis memorialístics valencians: anotacions dietarístiques i cròniques locals». Quaderns de filologia. Estudis literaris, XVI, 159-173.

Jané, O., Miralles, E., Fernández, I. (eds.) (2013). Memòria personal. Una altra manera de llegir la història. Barcelona: Universitat Autònoma de Barcelona (Col·1. «Monografies Manuscrits»).

JANÉ, O. (2013). «Memòria personal: la història i l'escriptura». Pròleg a: JANÉ, O., MiRALles, E., Fernández, I. (eds.) (2013). Memòria personal. Una altra manera de llegir la història. Barcelona: Universitat Autònoma de Barcelona (Col-1. «Monografies Manuscrits»), p. 7-10.

Jané, O., Poujade, P. (eds.) (2015). Memòria personal. Construcció i projecció en primera persona a l’Època Moderna. Madrid: Casa de Velázquez.

LLÀCER, A. (2015). «Aproximació a les fonts de Jaume Ramon Vila (AHCB, ms. B-100)». Mirabilia/medtrans, 1, 159-175. 
Llàcer, A. (2016). «El dietari de Jaume Ramon Vila, una obra fragmentada». Scripta, 8, 105-115.

— (2018). «Memòries o història? Sobre els límits dels gèneres en la literatura de l'edat moderna». Revista Internacional d'Humanitats, 42, 105-116.

MAndingorra, M. (2002). «La configuración de la identidad privada: diarios y libros de memorias en la baja Edad Media». Historia. Instituciones. Documentos, 29, 217-236.

Miralles, E. (2003). «La visió dels ciutadans: els dietaris personals». Barcelona Quaderns d'Història, 9, 207-232.

MNA = Manual de novells ardits vulgarment apellat Dietari del Antich Consell Barceloní, a cura de F. Carreras Candi et. al., dir., v. vir i viII. Barcelona: Ajuntament de Barcelona, 1898.

Mouysset, S. (2015). «Pourquoi laisser trace de sa vie ordinaire? France-Catalogne (XV ${ }^{\mathrm{e}}$ XIX ${ }^{\mathrm{e}}$ siècle». A: Jané, O., Poujade, P. (eds.). Memòria personal. Construcció i projecció en primera persona a l'època moderna. Madrid: Casa de Velázquez, 63-75.

Pujades, J. (1975). Dietari de Jeroni Pujades (1601-1605), a cura de J. M. Casas Homs, v. I. Barcelona: Rafael Dalmau.

Simon, A. (1988). «Memorias y diarios personales de la Cataluña Moderna». Historia Social, 2, 119-134.

-(1991). Cavallers i ciutadans a la Catalunya del Cinc-cents. Barcelona: Curial.

—(2004). «La historiografia del segle del Barroc (de Jeroni Pujades a Narcís Feliu)». A: Balcells, A. (ed.). Història de la historiografia catalana. Barcelona: Institut d'Estudis Catalans, 93-116.

- (2015). «Memòries i diaris personals de la Catalunya moderna. Del no res a la plètora». A: JAnÉ, O., Poujade, P. (eds.). Memòria personal. Construcció i projecció en primera persona a l'època moderna. Madrid: Casa de Velázquez, 17-30.

VILA, J. R. Dietari (1596-1601), AHCB, ms. B-100. 